\title{
O ABANDONO DIGITAL DE INCAPAZ E OS IMPACTOS NOCIVOS PELA FALTA DO DEVER DE VIGILÂNCIA PARENTAL
}

\author{
Fábia de Oliveira Rodrigues Maruco* ${ }^{1}$ \\ Lino Rampazzo**
}

\section{Resumo:}

O presente artigo apresenta a análise pormenorizada do tema abandono digital, fenômeno recente no ordenamento jurídico brasileiro, seus reflexos e os impactos causados aos incapazes ante à falta de vigilância parental no exercício do poder familiar. O estudo, feito pelo método dedutivo a partir de levantamento bibliográfico e documental ressalta a importância das medidas de proteção elencadas nos dispositivos legais e, em especial a Constituição Federal e Estatuto da Criança e do Adolescente além de decisões mais recentes dos Tribunais para a concretização da proteção.

Palavras-chave: Relações Familiares; Parentalidade Distraída; Abandono Digital; Proteção Legal; Intervenção Estatal

\section{THE DISABLED DIGITAL ABANDONMENT AND THE HARMFUL IMPACTS BY THE LACK OF PARENTAL SURVEILLANCE DUTY}

\begin{abstract}
:
This article presents a detailed analysis of the topic of digital abandonment, a recent phenomenon in the Brazilian legal system, its reflexes and the impacts caused to the incapacitated due to the lack of parental surveillance in the exercise of family power. The study, carried out by the deductive method based on a bibliographic y documentary survey, highlights the importance of the protection measures listed in the legal provisions and, in particular, the Federal Constitution and Statute of the Child and Adolescent, in addition to the most recent decisions of the Courts for the realization of protection .
\end{abstract}

Keywords: Family relationships; Distracted parenting; Digital Abandonment; Legal Protection; State Intervention

\section{Introdução}

A família, considerada a base da sociedade, passa por transformações ao longo do

\footnotetext{
*Fábia de Oliveira Rodrigues Maruco, Advogada, Mestre em Direitos Difusos e Coletivos do Centro Universitário Salesiano de São Paulo - Unidade Lorena - SP. E-mail: fabiamaruco@hotmail.com. ID Lattes: 533369251727579

**Lino Rampazzo, Pós-Doutor em Democracia e Direitos Humanos (Universidade de Coimbra). Doutor em Teologia (PUC Lateranense - Roma). Professor e Pesquisador no Programa de Mestrado em Direito do Centro Universitário Salesiano. E-mail: lino.rampazzo@ uol.com.br. ID Lattes: 7562078274681687
} 
tempo e goza de especial proteção do Estado, sobretudo em relação aos infantes e adolescentes.

Mas essa proteção deve ser exercida direta e mediatamente pela família, particularmente pelos pais. Nesse sentido, o Código Civil brasileiro considera a responsabilidade civil dos pais, bem como o poder familiar e a guarda.

O poder familiar consiste na autoridade dos pais em exercerem o dever de cuidar dos filhos, participar de sua vida e geri-la para benefício da criança e do adolescente. A guarda é o poder-dever dos pais de manterem os filhos sob sua vigilância, enquanto que a responsabilidade está estritamente ligada a essa vigilância e traz o encargo de supervisionar e assumir os resultados das condutas dos filhos.

Os pais são os principais influenciadores das ações das crianças e dos adolescentes, e a eles incumbe o dever de participar e monitorar os filhos para seu crescimento normal, hígido e digno. Isso não é exceção no meio digital, dado que esse é um reflexo do mundo real e possui os mesmos perigos.

Um dos maiores desafios do Direito de Família, nos tempos da era digital é a manutenção dos vínculo de afeto e de convivência. A tecnologia que é utilizada para a interação de pessoas acaba por surtir efeito contrário no âmbito familiar.

A paternidade distraída consiste na omissão do dever de cuidado em relação aos filhos, sendo o primeiro passo para o abandono digital, onde a interação maior é com o mundo virtual em detrimento do mundo real.

Os resultados disso são vínculos familiares empobrecidos, ocorrência de distúrbios comportamentais e omissão dos pais no cumprimento do seu papel de orientar seus filhos no uso indiscriminado do celular e transmissão de valores.

A aplicação das medidas de proteção legais se fazem importantes, como maneira de atuação do Estado na manutenção dos direitos das crianças e dos adolescentes, haja vista que são pessoas de direitos e se encontram em situação especial de desenvolvimento, merecendo proteção prioritária e integral, como delega a doutrina da Proteção Integral.

É a partir disso que este artigo pretende analisar quais são os atuais desafios da convivência familiar e a correspondente proteção legal. Em seguida considera a situação do empobrecimento das relações familiares diante de uma parentalidade distraída. E, por fim, examina a situação do abandono digital com suas possíveis consequências. 


\title{
1 Família: os desafios da convivência e a proteção legal
}

A família sempre foi considerada como a primeira e fundamental expressão da natureza social do homem. É realmente uma comunidade de pessoas caracterizada por existirem e viverem juntas. Somente as pessoas são capazes de viver "em comunhão". E, numa leitura mais especificamente teológica, emerge a referência exemplar ao "nós" divino da Trindade.

A família tem início na comunhão conjugal, que o Concílio Vaticano II classifica como "aliança", na qual o homem e a mulher "mutuamente se dão e recebem um ao outro" (JOÃO PAULO II, 1994, p. 1). Tal visão, de matriz explicitamente cristã, pode contribuir, também numa sociedade pluralista, para a valorização da instituição familiar.

Nesse sentido, na Carta dirigida às Famílias em 1994, o Papa João Paulo II ressaltava o ‘direito prevalecente dos pais' na educação dos filhos. Pelo 'princípio da subsidiariedade’ o Estado e a sociedade não podem substituir os pais nesta fundamental tarefa, mas apenas se colocam a serviço da família. Veja-se como expressou isso:

\begin{abstract}
Os pais são os primeiros e principais educadores dos próprios filhos e têm também neste campo uma competência fundamental: são educadores porque pais. Eles partilham a sua missão educadora com outras pessoas e instituições, tais como a Igreja e o Estado; todavia, isto deve verificar-se sempre na correta aplicação do princípio da subsidiariedade. Este implica a legitimidade e mesmo o ónus de oferecer uma ajuda aos pais, mas encontra no direito prevalecente deles e nas suas efetivas possibilidades o seu limite intrínseco e intransponível. O princípio da subsidiariedade põe-se, assim, ao serviço do amor dos pais, indo ao encontro do bem do núcleo familiar. $\mathrm{Na}$ verdade, os pais não são capazes de satisfazer por si sós a todas as exigências do processo educativo inteiro, especialmente no que toca à instrução e ao amplo sector da sociabilização. A subsidiariedade completa assim o amor paterno e materno, confirmando o seu carácter fundamental, porque qualquer outro participante no processo educativo não pode operar senão em nome dos pais, com o seu consenso e, em certa medida, até mesmo por seu encargo. (JOÃO PAULO II, 1994, p. 2).
\end{abstract}

A família atual é um sistema muito complexo e que passou por vários ciclos de desenvolvimento ao longo da história, transformando-se em razão das mudanças econômicas, religiosas, sociais e culturais. Viver em família é um desafio profundo.

Junto com as transformações, também aumentaram os desafios para manter uma boa relação entre os familiares. E isso sem falar nos obstáculos que a vida contemporânea trouxe 
ao cenário doméstico: longas jornadas de trabalho, exercício da tolerância e o ensino do respeito. Mirian Goldenberg assim se expressou sobre as atuais relações familiares:

(...) o retrato familiar que se desenha hoje se baseia na qualidade das relações. Há mais investimento em afeto, tempo e atenção. A divisão doméstica de tarefas decorre de uma negociação permanente. Justamente por isso, o que manterá essa nova família unida é o empenho de todos os envolvidos. Será preciso respeitar a individualidade de cada um e estimular o diálogo e a reciprocidade. Significa aceitar que nem todos os conflitos serão resolvidos e que temos que aprender a conviver com as diferenças. (GOLDENBERG, 2016, p. 1).

Vive-se, porém, numa sociedade individualista onde, na maioria das famílias, o valor da solidariedade mão é vivenciado. Cada um só pensa no seu prazer, no seu interesse e na sua liberdade. A solução não é simples e exige uma nova postura por parte da família. É preciso educar o filho para pensar no outro também. Mas, para repensar valores, é necessária a convivência: fazer uma refeição em família, assistir televisão juntos ou sentar-se para bater um papo para ver quais conceitos a criança está adquirindo. Se os pais não criam um espaço de diálogo, amanhã não saberão nada do filho (GOLDENBERG, 2016, p. 1).

O cuidado e o zelo devem ganhar destaque entre tantos deveres preceituados para esta instituição (RADAELLI; BATISTELA, 2019, p.2).

A família é cantada e decantada como base da sociedade (DIAS, 2015, p. 30) e por esta razão recebe mais proteção do Estado conforme disposto no artigo 226, da Constituição Federal:

Art. 226. A família, base da sociedade, tem especial proteção do Estado.

$\S 1^{\circ} \mathrm{O}$ casamento é civil e gratuita a celebração.

$\$ \mathbf{2}^{\mathbf{0}} \mathrm{O}$ casamento religioso tem efeito civil, nos termos da lei.

$\$ 3^{\circ}$ Para efeito da proteção do Estado, é reconhecida a união estável entre o homem e a mulher como entidade familiar, devendo a lei facilitar sua conversão em casamento.

$\S 4^{\mathbf{0}}$ Entende-se, também, como entidade familiar a comunidade formada por qualquer dos pais e seus descendentes.

$\S 5^{\circ}$ Os direitos e deveres referentes à sociedade conjugal são exercidos igualmente pelo homem e pela mulher.

$\S 6^{\circ} \mathrm{O}$ casamento civil pode ser dissolvido pelo divórcio.

$\S 7^{\circ}$ Fundado nos princípios da dignidade da pessoa humana e da paternidade responsável, o planejamento familiar é livre decisão do casal, competindo ao Estado propiciar recursos educacionais e científicos para o exercício desse direito, vedada qualquer forma coercitiva por parte de instituições oficiais ou privadas.

$\$ \mathbf{8}^{\circ}$ O Estado assegurará a assistência à família na pessoa de cada um dos que a integram, criando mecanismos para coibir a violência no âmbito de suas relações. 
A própria Declaração Universal dos Direitos do Homem estabelece que: "XVI 3. A família é o núcleo natural e fundamental e tem direito à proteção da sociedade e do Estado".

Há algum tempo se afirmava, nas antigas aulas de educação moral e cívica, que a família é a "célula mater" da sociedade. Apesar das aulas serem herança do período militar ditatorial, a frase ainda serve como luva no atual contexto, porque o artigo 226 da Constituição Federal dispõe claramente ser a família a base da sociedade tendo especial proteção do Estado (TARTUCE, 2019, p. 1068).

O influxo da chamada globalização impõe constante alteração de regras, leis e comportamentos. A mais árdua é mudar as regras do direito das famílias, porque diz respeito diretamente à vida das pessoas, a seus sentimentos.

O legislador não consegue acompanhar a realidade social, nem contemplar as inquietações da família contemporânea, pois a sociedade evolui, transforma-se, rompe com as tradições e amarras: o que gera a necessidade de oxigenação das leis. E, no campo mais específico das relações afetivas, a missão é muito mais delicada (DIAS, 2015, p. 31).

As alterações estruturais e funcionais no direito de família podem ser sentidas pelo estudo de seus princípios, muitos deles com previsão na Constituição de 1988 (TARTUCE, 2019, p. 1056).

O surgimento da Constituição Federal de 1988 refletiu diretamente no direito de família, considerando-a base da sociedade, independentemente do tipo de arranjo familiar em que esteja inserida. É uma regra de inclusão e atualmente tem como objetivo a realização e o desenvolvimento de todos os seus integrantes, que são sujeitos de direitos, e consequentemente munidos de dignidade. A esse respeito Sílvio de Salvo Venosa assim se expressou:

A Constituição de 1988 representou, sem dúvida, o grande divisor de águas do direito privado, especialmente, mas não exclusivamente, nas normas de direito de família. O reconhecimento da união estável como entidade familiar (art. 226, $\$ 7^{\circ}$ ) representou um grande passo jurídico e sociológico em nosso meio. É nesse diploma que se encontram princípios expressos acerca do respeito à dignidade da pessoa humana (art. $1^{\circ}$, III). Nesse campo, situam-se os institutos do direito de família, o mais humano dos direitos, como a proteção à pessoa dos filhos, direitos e deveres entre cônjuges, igualdade no tratamento entre estes, etc. Foi essa Carta Magna que também alçou o princípio constitucional da igualdade jurídica dos cônjuges e dos companheiros (art.226, $\S 5^{\circ}$ ) e igualdade absoluta dos filhos, não importando 
sua origem ou a modalidade de vínculo (art. 227, § $6^{\circ}$ ). Ainda, Constituição de 1988 escreve o princípio da paternidade responsável e o respectivo planejamento familiar (art.226, $\$ 7^{\circ}$ ). O Código Civil de 2002 complementou e estendeu esses princípios, mas, sem dúvida, a verdadeira revolução legislativa em matéria de direito privado e especificamente de direito de família já ocorrera antes, com essa Constituição. (VENOSA, 2007, p. 07).

Para Fabíola Santos Albuquerque (2010, p.30), tornou-se possível inferir um rol de princípios constitucionais aplicáveis ao direito de família, tais como os princípios da proteção da dignidade da pessoa humana, da igualdade, da afetividade e do melhor interesse da criança e do adolescente.

Quanto ao melhor interesse da criança e do adolescente, a Constituição da República Federativa do Brasil conferiu aos pais e responsáveis a plena liberdade em relação ao modo de educar e criar seus filhos, não dispondo de forma impositiva a forma como deve acontecer, partindo do princípio de que a vida íntima da família deve ser dotada de bom senso.

Um dos princípios que regem o Direito de família é justamente o princípio da liberdade, presente também no Código Civil, proibindo a qualquer pessoa e até mesmo ao Estado de interferir na constituição familiar, no seu planejamento, bem como no pleno exercício do poder familiar, como se pode vislumbrar nos artigos trazidos pelo Código Civil de 2002: “Art. 1513: É defeso a qualquer pessoa, de direito público ou privado, interferir na comunhão de vida instituída pela família” Bruna Rosado Radaelli e Caroline Gassen Batistela assim se expressaram no $5^{\circ}$ Congresso Internacional de Direito e Contemporaneidade realizado na Universidade Federal de Santa Maria (RS), criticando qualquer tipo de interferência na família:

Na família constituída pela comunhão de vida é defesa a interferência de
quem quer que seja. Nem mesmo interferência estatal. Deverá o estado
assegurar a proteção à família, observando a inviolabilidade da intimidade
das pessoas. Vislumbra-se que por este princípio a entidade familiar tem
liberdade diante da sociedade e do Estado: O princípio da dignidade da
pessoa humana é a sustentação dos ordenamentos jurídicos da atualidade, eis
que é o vértice do Estado de Direito e significa para o Direito de Família o
respeito à autonomia dos sujeitos, à sua liberdade, bem como uma dignidade
igualitária para todas as formas de família. O princípio da igualdade prevê
que devem ser tratados iguais os iguais e desiguais os desiguais na exata
medida de sua igualdade ou desigualdade. Já, no âmbito do direito de família
se prevê a igualdade entre cônjuges e companheiros, bem como entre os
filhos, sejam eles havidos ou não da relação do casamento. O princípio da
afetividade está relacionado com os laços afetivos que envolvem os
membros de uma família, sejam eles conjugais ou parentais. Por fim, o
princípio do melhor interesse da criança e do adolescente está previsto no
artigo 227 , da CF: é dever da família, da sociedade e do Estado assegurar à 
criança e ao adolescente, com absoluta prioridade, o direito à vida, à saúde, à alimentação, à educação, ao lazer, à profissionalização, à cultura, à dignidade, ao respeito, à liberdade e à convivência familiar e comunitária, além de colocá-los a salvo de toda forma de negligência, discriminação, exploração, violência, crueldade e opressão. (RADAELLI; BATISTELA, 2019, p. 4).

A formação de uma família envolve um planejamento familiar, sobretudo a obrigação dos pais em fornecerem educação e criação aos filhos, fixando as responsabilidades dos pais individualmente na formação do caráter dos filhos.

Contudo, na ocorrência da omissão dos pais no dever de cuidado dos filhos, o Estado intervém por meio de reprimendas, tanto de ordem civil quanto criminal, podendo ocorrer a responsabilização pelos crimes de abandono material e intelectual positivados nos artigos 244 e 246 do Código Penal Brasileiro:

Art 244, CP. Deixar, sem justa causa, de prover a subsistência do cônjuge, ou de filho menor de 18 (dezoito) anos ou inapto para o trabalho, ou de ascendente inválido ou maior de 60 (sessenta) anos, não lhes proporcionando os recursos necessários ou faltando ao pagamento de pensão alimentícia judicialmente acordada, fixada ou majorada; deixar, sem justa causa, de socorrer descendente ou ascendente, gravemente enfermo: (Redação dada pela Lei $\mathrm{n}^{\circ} 10.741$, de 2003)

Pena - detenção, de 1 (um) a 4 (quatro) anos e multa, de uma a dez vezes o maior salário mínimo vigente no País. (Redação dada pela Lei $n^{\circ} 5.478$, de 1968)

Parágrafo único - Nas mesmas penas incide quem, sendo solvente, frustra ou ilide, de qualquer modo, inclusive por abandono injustificado de emprego ou função, o pagamento de pensão alimentícia judicialmente acordada, fixada ou majorada. (Incluído pela Lei $n^{\circ} 5.478$, de 1968)

Art 246, CP. Deixar, sem justa causa, de prover à instrução primária de filho em idade escolar:

Pena - detenção, de quinze dias a um mês, ou multa.

A Constituição Federal de 1988 prevê o dever legal dos pais em educar seus filhos em seu artigo 229, o qual preceitua que "os pais têm o dever de assistir, criar e educar os filhos, e os filhos maiores têm o dever de ajudar e amparar os pais na velhice, carência ou enfermidade".

Seguindo a mesma linha, a Lei 8.069/90 (Estatuto da Criança e do adolescente) prevê não somente obrigações materiais dos pais em relação aos filhos, como também as obrigações morais, de afeto e psíquicas:

Art. $3^{\circ}$. A criança e o adolescente gozam de todos os direitos fundamentais inerentes à pessoa humana, sem prejuízo da proteção integral de que trata esta Lei, assegurando-se lhes, por lei ou por outros meios, todas as 
oportunidades e facilidades, a fim de lhes facultar o desenvolvimento físico, mental, moral, espiritual e social, em condições de liberdade e de dignidade. Parágrafo único. Os direitos enunciados nesta Lei aplicam-se a todas as crianças e adolescentes, sem discriminação de nascimento, situação familiar, idade, sexo, raça, etnia ou cor, religião ou crença, deficiência, condição pessoal de desenvolvimento e aprendizagem, condição econômica, ambiente social, região e local de moradia ou outra condição que diferencie as pessoas, as famílias ou a comunidade em que vivem.

Art. 22. Aos pais incumbe o dever de sustento, guarda e educação dos filhos menores, cabendo-lhes ainda, no interesse destes, a obrigação de cumprir e fazer cumprir as determinações judiciais. Parágrafo único. A mãe e o pai, ou os responsáveis, têm direitos iguais e deveres e responsabilidades compartilhados no cuidado e na educação da criança, devendo ser resguardado o direito de transmissão familiar de suas crenças e culturas, assegurados os direitos da criança estabelecidos nesta Lei.

$\mathrm{O}$ afeto talvez seja apontado, atualmente, como principal fundamento das relações familiares. Mesmo não constando no texto constitucional, como sendo um direito fundamental, pode-se afirmar que ele decorre da valorização constante da dignidade da pessoa humana e da solidariedade (DIAS, 2009, p. 69).

Do mesmo modo, concluindo que o afeto tem valor jurídico, aponta a Ministra Nancy Andrighi:

A quebra de paradigmas do Direito de Família tem como traço forte $\underline{a}$ valorização do afeto e das relações surgidas da sua livre manifestação, colocando à margem do sistema a antiga postura meramente patrimonialista ou ainda aquela voltada apenas ao intuito e procriação da entidade familiar. Hoje, muito mais visivelmente alcançam as relações afetivas, sejam entre pessoas de mesmo sexo, sejam entre o homem e a mulher, pela comunhão de vida e de interesses, pela reciprocidade zelosa entre seus integrantes (...) (STJ, 2010, grifo nosso).

As relações afetivas familiares sofrem, atualmente, a intervenção da internet, mais especificamente, das redes sociais. Essa nova forma de interação vem aos poucos afastando os entes familiares, chegando-se ao ponto de reduzir a frequência dos diálogos.

Imagine-se uma casa em que os adultos saem cedo para ir trabalhar e as crianças e jovens vão para a escola. Depois de um dia inteiro de muitas atividades para todos, eles se juntam na sala ou durante o jantar. Mas, estar junto ali, fisicamente, não mais implica em diálogo. Cada um pega o seu smartphone e parte para o espaço virtual, seja em conversas pelo Facebook e WhatsApp, nos jogos on-line e tantas outras possibilidades notablet.

E se os adultos já sofrem prejuízos mesmo com a maturidade adquirida com o tempo, nem se 
fala das crianças, que se encontram em constante desenvolvimento integral. Atividades sem movimento não fazem tão bem aos pequenos quanto aquelas que mexem com o corpo, como pega-pega, escondeesconde, futebol, e muitas outras. Isso porque os pequenos precisam brincar e gastar a grande quantidade de energia que têm. Imagine-se uma criança com apenas quatro anos que já utiliza o tablet melhor que muitos adultos! A respeito disso, Wellington Carvalho comenta:

Se o afeto e o cultivo de outros bons sentimentos não forem bem valorizados, possivelmente a tecnologia favorecerá um distanciamento maior, propiciando um isolamento entre os membros da família. Ou seja, cada um fica circunscrito ao seu espaço virtual. (CARVALHO, 2016, p.1).

O ambiente virtual desenvolve alguns aspectos positivos na criança, como os intelectuais, porém empobrece os relacionamentos sociais. Mesmo assim, é importante o convívio pessoal com quem está aoredor.

Uma família sem diálogo, onde não há comunicação apesar de estarem juntos, é uma situação extrema de solidão no grupo familiar, segundo Maria Helena Marzabal Paulino (...) Muitos têm compulsão pela internet. A pessoa não vive sem ela e se isola do mundo presencial, acabando até em quadro depressivo. (CARVALHO, 2016, p. 1).

A ruptura dos vínculos familiares em virtude do mundo virtual é algo que deve servir de alerta para as famílias, principalmente quando relacionadas a parentalidade distraída e ao abandono digital.

\section{A parentalidade distraída e o empobrecimento das relações familiares}

No decorrer do Século XX, a estrutura familiar sofreu significativas transformações, principalmente em decorrência das profundas alterações no papel da mulher na sociedade. Ela passou a trabalhar fora de casa, a contribuir financeiramente para o sustento do lar e a decidir quantos filhos iria conceber.

Essas mudanças sobrevieram concomitantemente com o desenvolvimento tecnológico vindo a atingir de maneira substancial a instituição familiar.

As transformações tecnológicas proporcionaram aos pais, crianças e adolescentes maior entretenimento digital como uso da televisão, dos computadores, dos celulares e outros tipos de mídias.

O uso descontrolado desses meios de comunicação vêm desencadeando inúmeros transtornos que, de forma desmedida, acaba por afetar a vida das pessoas, tanto na comunidade, quanto no núcleo familiar.

Dados recentes do Instituto Brasileiro de Geografia e Estatística - IBGE (2017; 2018) afirmam que a internet faz parte do cotidiano de 74,9\% dos domicílios do Brasil, sendo 
que o meio de acesso por aparelhos de celular chega a $97 \%$.

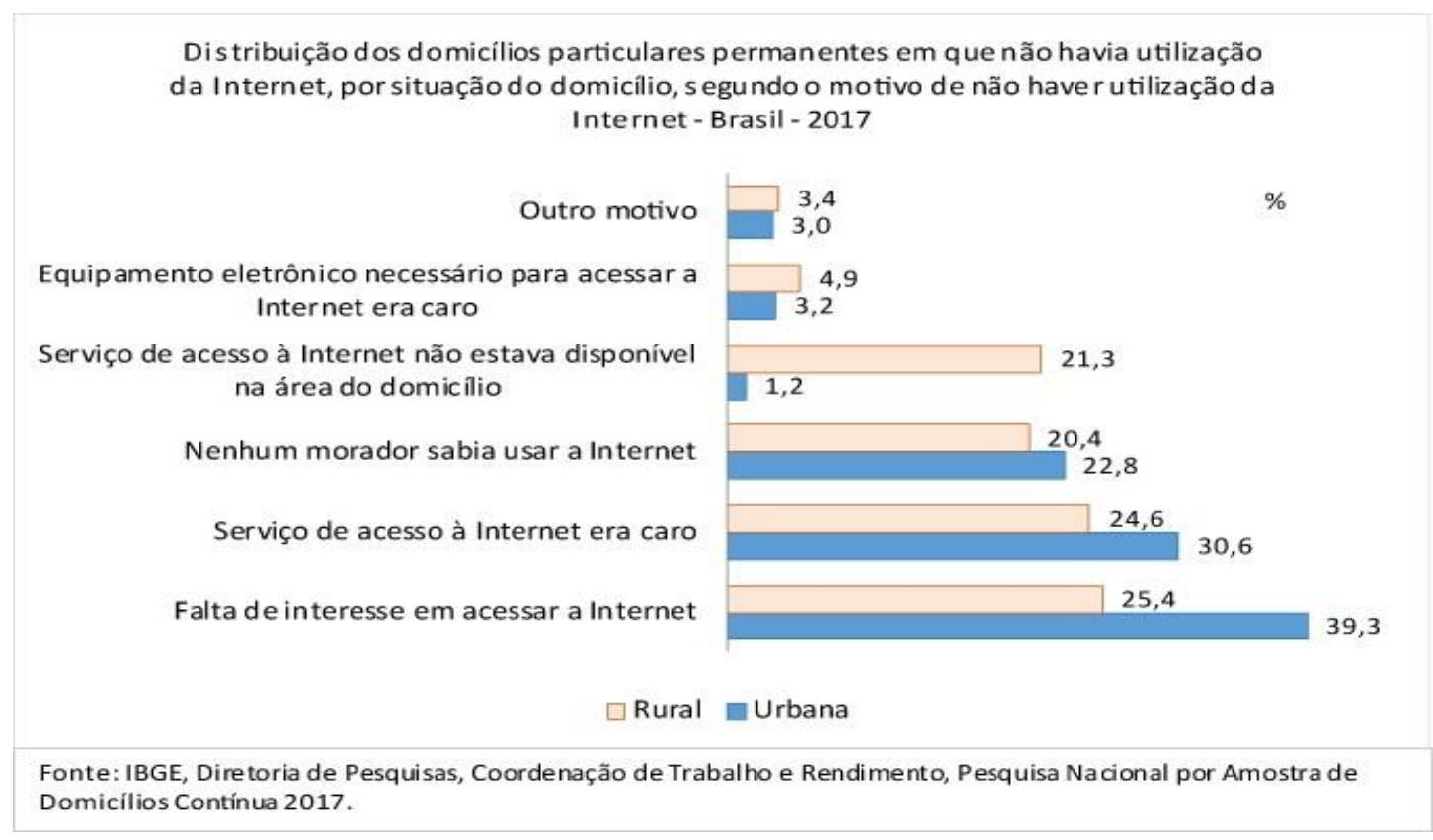

Os celulares acompanham as pessoas nas mais diversas tarefas, ocupam a concretização de encontros que passam a ser via aplicativos de conversa e se tornaram vilões quando o assunto é estabelecer um diálogo sem nenhuma interferência midiática.

Chegou-se ao ponto que a tecnologia progressista se tornou algo que prejudica, exclui e compromete as relações humanas.

Há mais de vinte anos, mais precisamente em 1998, a pesquisadora Linda Stone cunhou o termo "atenção parcial contínua" para falar desse novo estilo de relação entre pais e filhos que afeta negativamente a comunicação responsiva, base da aprendizagem humana. Atualmente denomina-se parentalidade distraída (PARENTALIDADE, 2019).

Este fenômeno surge como resultado de uma realidade sociológica das famílias vigentes onde a interrupção ou não existência de interação de pais e filhos acaba afastando, direta ou indiretamente, todos os sujeitos pertences àquele grupo.

Percebe-se um tipo de abandono em que indivíduos e máquinas disputam a atenção de pessoas que em tese deveriam estar aptas e dispostas a contribuir para a formação de uma criança ou adolescente. A respeito disso Leandro Soares Lomeu escreveu:

A parentalidade distraída coloca em voga uma espécie de releitura do abandono familiar, abandono este que não significa um afastamento físico de pais e filhos, mas um espaço abstrato que marca tanto quanto uma separação 
fática. As figuras do afeto e do cuidado parecem um tanto quanto prejudicadas, visto que ser gentil e cuidadoso com seu filho, nos dias hodiernos, é presenteá-lo com um celular de última geração, por exemplo. Embora não pareça, a troca de momentos de diálogo por conversas em aplicativos de bate-papo, é também abrir mão da vivência familiar, é substituir o lazer propriamente dito por situações em que o uso de computadores e celulares ocupam a maior espaço do tempo livre dos adultos. (LOMEU, 2010, p. 106).

Segundo estudos realizados nos Estados Unidos (BEKER,2018), 35\% das crianças se queixam que os pais ficam durante as refeições olhando para a tela do celular. E destes mesmos pais apenas 5\% confirmam tal informação. Isso significa que os pais olham o celular automaticamente sem perceber. Como resultados disso há vínculos empobrecidos, ocorrência de baixa autoestima, distúrbios de comportamento, diminuição do convívio com os filhos.

Quando se trata do desenvolvimento infantil, os pais precisam se preocupar não só com o tempo de tela de seus filhos, mas também com o seu próprio. Isso não quer dizer que não seja importante prestar atenção na relação dos pequenos com a tecnologia, algo que apresenta diversos riscos, mas também é fundamental falar mais sobre a divisão de atenção que os adultos fazem entre seus smartphones e as crianças. A distração crônica dos adultos em função do celular pode ter efeitos duradouros no desenvolvimento cognitivo e emocional de seus filhos (PARENTALIDADE, 2019, p.1).

Os pais deixam, com isso, de cumprir seu papel de orientar os filhos quanto ao uso indiscriminado do celular e ensinar educação e valores.

Crianças e Adolescentes que crescem, em lares assim, possuem tendência a ser agressivos, rebeldes, a desafiarem a autoridade de pessoas mais velhas, podem vier a praticar ou mesmo a sofrer bullying, podem ser acometidos de distúrbios alimentares e de ordem psicológica (McDANIEL; RADESKY, 2018, p.102). A respeito disso Letícia Prazeres Falcão observa:

Por não possuírem a devida atenção, orientação e ternura que deveria ser advinda dos pais, passam a procurar diálogos com terceiros, sentem a necessidade de suprir essa carência, sejam em um ambiente também virtual ou no uso de remédios, e assim acaba que se forma um ciclo vicioso em que a ausência de afeto pode gerar sujeitos vazios de princípios e inseguros quanto a sentimentos e relações subjetivas. (FALCÃO, 2019, p. 56).

A convivência em pais e filhos é posta à prova de modo a questionar até onde cabem 
responsabilizações jurídicas frente à parentalidade distraída em detrimento da opção por telas brilhantes.

A parentalidade distraída (FALCÃO, 2019, p. 58) caracteriza-se como uma espécie de releitura do abandono familiar, abandono este que não significa um afastamento físico de pais e filhos, mas um espaço abstrato que marca tanto quanto uma separação fática.

É forçoso reconhecer que a atenção virtual não pode substituir o vínculo de afeto existente nas relações familiares.

O princípio da afetividade possui uma construção axiológica, uma espécie de compilado sistemático em que a ternura, a paixão, o afeto, a dedicação e a atenção devem estar presentes e perpetuar as relações parentais.

Embora não haja uma previsão expressa na Carta Magna, a afetividade surge com o enlace do Princípio da Proteção Integral à Criança e o da Dignidade da Pessoa Humana. Reconhece-se, assim, que o afeto é primordial para o crescimento daquela criança enquanto cidadão e sujeito de direitos.

O Estatuto da Criança e do Adolescente, em seu artigos $3^{\circ}$, e o art. 1638, II, do Código Civil, pressupõem garantias essenciais àquele considerado como ser em formação e alerta para a perda do poder familiar. Defende-se que atos de abandono, inclusive afetivo, são motores propulsores de impactos na esfera física, moral, espiritual e social daquele filho, pois há uma interrupção do dever de cuidado que deveria ser contínuo e uma fragilização de hábitos tão essencialmente necessários.

A rapidez e o excesso de informações, de ferramentas tecnológicas, aliados à rotina sobrecarregada, facilitam que as relações entre as pessoas aconteçam com mais velocidade e com menos qualidade e compromisso de continuidade.

Vejam-se, então, a seguir os citados artigos.

ECA - Lei no 8.069 de 13 de julho de 1990

Dispõe sobre o Estatuto da Criança e do Adolescente e dá outras providências.

Art. $3^{\circ}$ A criança e o adolescente gozam de todos os direitos fundamentais inerentes à pessoa humana, sem prejuízo da proteção integral de que trata esta Lei, assegurando-se-lhes, por lei ou por outros meios, todas as oportunidades e facilidades, a fim de lhes facultar o desenvolvimento físico, mental, moral, espiritual e social, em condições de liberdade e de dignidade.

Parágrafo único. Os direitos enunciados nesta Lei aplicam-se a todas as crianças e adolescentes, sem discriminação de nascimento, situação familiar, 
idade, sexo, raça, etnia ou cor, religião ou crença, deficiência, condição pessoal de desenvolvimento e aprendizagem, condição econômica, ambiente social, região e local de moradia ou outra condição que diferencie as pessoas, as famílias ou a comunidade em que vivem. (incluído pela Lei $\mathrm{n}^{\circ}$ 13.257, de 2016).

Lei $\mathrm{n}^{\circ} 10.406$ de 10 de Janeiro de 2002

Institui o Código Civil.

\section{SUBTÍTULO II}

Das Relações de Parentesco

Art. 1.638. Perderá por ato judicial o poder familiar o pai ou a mãe que:

I - castigar imoderadamente o filho;

II - deixar o filho em abandono;

(...). (Grifo nosso).

Discute-se, por outro lado, sobre a possibilidade dos pais serem responsabilizados pela parentalidade distraída, embora se frise que não há legislação acerca do assunto. Contudo, é possível delimitar alguns pontos que merecem reflexão.

Um primeiro seria se a parentalidade distraída por si só poderia ser considerada ato ilícito (art. 186-187 do Código Civil), considerando o abandono afetivo. Constata-se, a respeito disso, a conduta humana de não dar atenção, não cuidar, não orientar, não aconselhar, não conviver com o filho em decorrência do uso intenso e desproporcional de mídias tecnológicas.

Outro ponto seria a negligência afetiva por parte dos pais, que gera um abandono afetivo oriundo de um descuido parental, como sendo fruto da preferência virtual.

Assim entende a Jurisprudência:

CIVIL E PROCESSUAL CIVIL. FAMÍLIA. ABANDONO AFETIVO. COMPENSAÇÃO POR DANO MORAL. POSSIBILIDADE. 1. Inexistem restrições legais à aplicação das regras concernentes à responsabilidade civil e o consequente dever de indenizar/compensar no Direito de Família. 2. O cuidado como valor jurídico objetivo está incorporado no ordenamento jurídico brasileiro não com essa expressão, mas com locuções e termos que manifestam suas diversas desinências, como se observa do art. 227 da $\mathrm{CF} / 88$. 3. Comprovar que a imposição legal de cuidar da prole foi descumprida implica em se reconhecer a ocorrência de ilicitude civil, sob a forma de omissão. Isso porque o non facere, que atinge um bem juridicamente tutelado, leia-se, o necessário dever de criação, educação e companhia - de cuidado - importa em vulneração da imposição legal, exsurgindo, daí, a possibilidade de se pleitear compensação por danos morais por abandono psicológico. 4. Apesar das inúmeras hipóteses que minimizam a possibilidade de pleno cuidado de um dos genitores em relação à sua prole, existe um núcleo mínimo de cuidados parentais que, para além do mero cumprimento da lei, garantam aos filhos, ao menos quanto à 
afetividade, condições para uma adequada formação psicológica e inserção social. 5. A caracterização do abandono afetivo, a existência de excludentes ou, ainda, fatores atenuantes - por demandarem revolvimento de matéria fática - não podem ser objeto de reavaliação na estreita via do recurso especial. 6. A alteração do valor fixado a título de compensação por danos morais é possível, em recurso especial, nas hipóteses em que a quantia estipulada pelo Tribunal de origem revela-se irrisória ou exagerada. 7. Recurso especial parcialmente provido. (S.T.J., 2012, grifo nosso).

Judicializar a distração da parentalidade é, pois, algo sério, devendo ser reavaliado o dever jurídico, moral, social na contribuição da feitura de um cidadão, é ter a consciência que em alguns momentos deixar o telefone celular de lado e valorizar situações e momentos com seus filhos é algo que não retrocede.

Talvez a ingerência de meios alternativos para a resolução de conflitos seja algo mais viável, a saber: proporcionar que pais e filhos conversem a respeito; ou ainda, oferecer soluções que vão nutrir o sentimento e conciliar o dever parental, seja algo mais razoável a ser feito.

Por fim, deixar o celular dos adultos e das crianças longe da mesa de jantar, ou do tempo de contação de histórias antes de dormir, pode parecer coisa pequena, mas o efeito cumulativo dessas atitudes é duradouro.

\section{Abandono digital}

O abandono digital foi uma expressão cunhada no Brasil por Patricia Peck Pinheiro, advogadae expoente em Direito Digital, como uma nova forma de responsabilidade civil.

Entende que a internet é a "nova rua" - terra de ninguém, porque antes as crianças brincavam nas ruas e hoje isso é raro.

Abandono digital é a negligência dos pais com relação à segurança dos filhos no ambiente virtual. $\mathrm{O}$ alcance da internet, sobretudo o impacto das redes sociais, pode gerar efeitos nocivos diante da vulnerabilidade das crianças e dos adolescentes (PINHEIRO, 2017, p.1).

A ideia de abandono fere princípios como o da Solidariedade Familiar, da Dignidade da Pessoa Humana, da Responsabilidade e Proteção Integral à Criança, fere preceitos constitucionais e infraconstitucionais de modo a impactar para além de uma esfera privada daquele jovem (LÔBO, 2009, p. 100).

Atenta-se que o abandono digital pode se dar de variadas formas, como por exemplo, 
o pai que perde o tempo de convivência com seu filho por lhe proporcionar a posse diária e durante horas de um tablet para que a criança não dê trabalho algum ou a utilização de aplicativos que não são para a faixa etária da criança ou do adolescente.

Ironicamente, pais também cometem abandono digital quando permanecem horas completamente conectados na internet e, dessa forma, deixam de prestar atenção ao conteúdo que o filho está acessando nos celulares, computadores e tablets.

Para uma família "viciada" no ambiente digital a quebra do dever de cuidado entre seus membros é um passo quase que inevitável.

A respeito disso Flavio Tartuce escreveu recentemente:

Para quem defende um reconhecimento jurídico desse desamparo e coloca a figura da responsabilidade civil, há a constatação do abandono afetivo enquanto uma espécie de ato ilícito, que atinge honra, integridade física e psicológica de um indivíduo (art. 12 do Código Civil), ofende também a ampla noção do dever de educação por parte dos pais e responsáveis gerando assim algo que "compense" a rejeição praticada. (TARTUCE, 2009, p. 1072).

O que se preza é a correta consciência da relevância da tutela daquele pai para com seu dependente: o dever de cuidado deve sobrepor uma mera cautela patrimonial e sim valorizar elementos intrínsecos ao desenvolvimento e proteção de uma criança ou adolescente.

Há de ressaltar que o ordenamento jurídico pátrio impõe aos pais e/ou responsáveis legais esse dever de cuidado em grau máximo, previsto desde a Constituição Federal (art. 227, $\S 4^{\circ}$ ) e até a legislação extravagante, citando-se aqui especificamente o Código Civil (arts. 1.630, 1.631, 1.634, I e X, 1.637, 1.638, I a IV) e o Estatuto da Criança e do Adolescente (arts. $3^{\circ}, 4^{\circ}, 5^{\circ}$ e 249$)$.

A doutrina vem conhecendo a denominação "abandono digital", que consiste na negligência parental provocada por atos omissos dos genitores que descuidam da segurança dos filhos no ambiente cibernético proporcionado tanto pela Internet, como pelas redes sociais, não evitando os efeitos nocivos delas diante de inúmeros riscos.

É um tema ainda novo e por isso ainda não houve um debate entre os doutrinadores de forma aprofundada sobre esse tipo específico de abandono, mas há julgados condenando pais, devido a sua responsabilidade parental, pelos atos ilícitos praticados pelo menor na Internet, como ocorreu no Tribunal de Justiça do Rio Grande do Sul em sua $6^{\text {a }}$ Câmara Cível: 
Trata-se de um menor que praticava na sua residência cyberbullying, inclusive utilizando o computador da sua mãe, o menor postava mensagens com teor ofensivo além de fazer montagens fotográficas levianas, como nas quais o autor de tal processo aparecia com chifres. Logo depois, o mesmo começou a receber mensagens com conteúdo ofensivo, no qual, o fez ingressar com uma ação cautelar visando a identificação do proprietário do computador que postava e enviava tais mensagens, chegando ao nome da mãe de um colega de turma. A mãe alegou em sua contestação que outros três jovens amigos do filho também faziam uso do seu computador e não poderia ser responsabilizada visto que não possuía conhecimento do feito. Segundo a relatora e desembargadora do caso Pires, aos pais incumbe o dever de guarda, orientação e zelo pelos filhos menores, respondendo civilmente pelos ilícitos praticados, uma vez ser inerente ao poder familiar, conforme o artigo 932 do Código Civil. Em primeiro grau, a Juíza em sua sentença argumentou que: Os fatos são claros: em face da ausência de limites que acomete muitos jovens, vide os inúmeros casos de bullying e atrocidades cometidas por adolescentes que vêm a público, o filho da ré, e quem sabe outros amigos, resolveram ofender, achincalhar e fazer com que o autor se sentisse bobo perante a comunidade de Carazinho. (RIO GRANDE DO SUL, 2009, grifo nosso).

Ficou demonstrado nesse julgado que houve o abandono digital por parte da ascendente materna que forneceu ao seu filho o acesso, tanto da Internet, como de seu computador, sem a devida precaução com o monitoramento dos atos do menor visto que a própria confessou que não tinha conhecimento da prática feita pelo filho.

Contudo, há situações ainda mais graves, como a que envolve a tentativa ou suicídio de menores, tanto podendo ser ocasionado pelo cyberbullying, como por outras atitudes, por exemplo, a divulgação de imagens e vídeos sensuais na rede mundial de computadores.

Outro caso, que também ocorreu no Rio Grande do Sul, trata exatamente do vazamento de vídeo íntimo de uma menor com seu ex-namorado: a adolescente teve sua privacidade violada de tal forma que tentou o suicídio. Eis, a respeito disso, o posicionamento do Tribunal de Justiça.

Infelizmente, esse caso não é o único e milhares de jovens e adolescentes são expostos seja por imagens, seja por vídeos íntimos que são divulgados sem a sua autorização. Em seu voto, o desembargador relator sustentou que: [...] $\mathrm{O}$ fato de a autora ter se deixado filmar em cena íntima pelo ex-namorado não lhe conferia o direito de divulgar a terceiros e muito menos permitir que circulasse na internet a gravação contendo a cena sexual. Ao assim agir $\underline{\mathbf{o}}$ 
demandado praticou ato ilícito de intensa reprovabilidade [...]. $\underline{\mathrm{A}}$ menor necessitou de tratamento psiquiátrico, tentou suicídio, e, em razão do bullying e das humilhações sofridas acabou transferida de escola juntamente com a irmã, bem ainda foi reprovada no ano letivo. (RIO GRANDE DO SUL, 2016, grifo nosso).

A internet não é um lugar seguro para uma criança ou um adolescente ficarem sozinhos.

E os pais que não fizerem nada a respeito, mesmo sabendo dos riscos a que os seus filhos menores estão sendo submetidos na rede mundial de computadores, devem ser culpabilizados e responsabilizados pelo abandono digital cometido, vez que o filho estará sendo prejudicado de forma permanente para o resto da vida (DINIZ, 2011, p. 98-99).

\section{Conclusão}

Viver em família é um desafio profundo na era digital, sobretudo porque os tempos mudaram e, mesmo que se queira repetir o comportamento imposto pelos pais da geração passada, isso já não é mais possível.

A formação de uma família exige dos pais a busca constante de conhecimento para educar os seus filhos.

A responsabilidade dos pais em orientar seus filhos, principalmente no uso das redes sociais, fez com que o legislador brasileiro impusesse sanções em caso de omissão. Isto porque o mundo virtual é o lugar onde crianças e adolescentes interagem o tempo todo.

O Direito de Família precisa se alertar para isso. Mas, antes disso, é preciso o cuidado dos pais em estabelecer horários de uso, esclarecendo as crianças e os adolescentes acerca dos riscos do uso indiscriminado que as redes sociais podem ocasionar, além de estabelecer com os filhos uma relação de confiança. Caso contrário, os pais estariam incorrendo em abandono digital.

Por isso se os pais, mesmo sabendo dos riscos que os seus filhos estão sendo submetidos na rede mundial de computadores, não fizerem nada a respeito, devem ser culpabilizados tanto pelos atos que as crianças e os adolescentes cometerem para com os outros, devendo haver a responsabilidade pelo abandono digital cometido.

\section{REFERÊNCIAS}


ALBUQUERQUE, Fabíola Santos. Famílias no Direito Contemporâneo. Salvador: Juspodivm, 2010.

BATISTELA, Caroline G.; RADAELLI, B. R. O abandono digital e a exploração sexual infantil. In: $5^{\circ}$ CONGRESSO INTERNACIONAL DE DIREITO E CONTEMPORANEIDADE: Mídias e Direitos da Sociedade em Rede, 2019, Santa Maria. a Convergência Digital e a Vulnerabilidade de Crianças e Adolescentes na Sociedade de Consumo, 2019. Disponível em: https://www.ufsm.br/cursos/pos-graduacao/santamaria/ppgd/wp-content/uploads/sites/563/2019/09/11.9.pdf. Acesso em: 20 mar. 2020.

BEKER, Daniel. Parentalidade Distraída. [Entrevista concedida a Pedro Bial]. 6 set. 2018. Disponível em: https://globoplay.globo.com/v/7002424/. Acesso em: 20 mar. 2020.

BRASIL. Lei 8.069 de 13 de julho de 1990. Dispõe sobre Estatuto da Criança e do Adolescente e dá outras providências. Disponível em: http://www.planalto.gov.br/ccivil_03/leis/18069.htm. Acesso em: 01 abr. 2020.

BRASIL. Lei 10.406, de janeiro de 2002. Institui o Código Civil. Disponível em: http://www.planalto.gov.br/ccivil_03/leis/2002/110406.htm. Acesso em: 01 abr. 2020.

CARVALHO, Wellington. Relacionamento familiar: internet aproxima ou distancia as pessoas que estão na nossa casa? Boavontade.com, 22/09/2016 Disponível em: https://www.boavontade.com/pt/tecnologia/relacionamento-familiar-internet-aproxima-oudistancia-pessoas-que-estao-na-nossa-casa. Acesso em: 30 mar. 2020.

DE MORAES, Dênis. Sociedade midiatizada. Rio de Janeiro: Mauad, 2018.

DIAS, Maria Berenice. Manual de Direito das Famílias. 5. ed. São Paulo: Revista dos Tribunais, 2009.

DIAS, Maria Berenice. Manual de direito das famílias. São Paulo: Revista dos Tribunais, 2015.

DINIZ, Maria Helena. Curso de direito civil brasileiro: direito de família. 26. ed. São Paulo: Saraiva, 2011.

FALCÃO, Letícia Prazeres. O fenômeno da parentalidade distraída e abandono afetivo quanto custa o cuidado na sociedade tecnológica. Revista de Direito de Família e Sucessão, Goiânia v. 5, n. 1, p. 56-72, jan./jun. 2019. Disponível em: https://www.indexlaw.org/index.php/direitofamilia/article/view/5591/pdf. Acesso em: 21 mar. 2020.

GOLDENBERG, M. Velho é lindo! Rio de Janeiro: Civilização Brasileira, 2016

GOMES, Amanda. Abandono digital no direito das famílias. Disponível em:

https://www.youtube.com/watch?v=3QrWznGLwTU Youtube. 11 de agosto de 2017. Acesso em: 21 mar. 2020.

IBGE. Internet chega a três em cada quatro domicílios no país. Disponível em: 
https://agenciadenoticias.ibge.gov.br/agencia-sala-de-imprensa/2013-agencia-denoticias/releases/23445-pnad-continua-tic-2017-internet-chega-a-tres-em-cada-quatrodomicilios-do-pais. Acesso em: 6 abr. 2020.

JOÃO PAULO II. Gratissimam Sane: Carta do Papa João Paulo II às famílias. 2 fev. 1994. Disponível em: http://www.vatican.va/content/john-paul-ii/pt/letters/1994/documents/hf_jpii_let_02021994_families.html. Acesso em: 16 mar. 2020.

LÔBO, Paulo. Direito Civil: Família. 2. ed. São Paulo: Saraiva, 2009.

LOMEU, Leandro Soares. Afeto, abandono, responsabilidade e limite: diálogos sobre ponderação. Revista IOB de Direito de Família, Porto Alegre: Síntese, v. 11, p. 105-117, 2010.

MCDANIEL, Brandon T.; RADESKY, Jenny S. Technoference: Parent distraction with technology and associations with child behavior problems. Child development, v. 89, n. 1, p.100-109, 2018. Disponível em: https://onlinelibrary.wiley.com/doi/full/10.1111/cdev.12822. Acesso em: 10 mar. 2020.

PARENTALIDADE distraída: o mal dos adultos que dão mais atenção às telas do que às crianças. Rede Decisão, 22 set. 2019. Disponível em: https://www.rededecisao.com.br/single-post/2019/09/22/Parentalidade-distra\%C3\%ADda-omal-dos-adultos-que-d $\% \mathrm{C} 3 \% \mathrm{~A} 30-$ mais-aten $\% \mathrm{C} 3 \% \mathrm{~A} 7 \% \mathrm{C} 3 \% \mathrm{~A} 3 \mathrm{o}-\% \mathrm{C} 3 \% \mathrm{~A} 0$ s-telas-do-que\%C3\%A0s-crian\%C3\%A7as. Acesso em: 10 mar. 2020.

PEREIRA, Rodrigo da Cunha. O que significa abandono digital e qual o impacto na vida dos filhos. Disponível em: http://www.rodrigodacunha.adv.br/o-que-significa-abandonodigital-e-qual-o-impacto-na-vida-dos-filhos/. Acesso em: 20 mar. 2020.

PINHEIRO, Patrícia Peck. Abandono digital. HuffPost Brasil, 26 jan. 2017. Disponível em: http://www.huffpostbrasil.com/patricia-peck-pinheiro/abandonodigital_a_21670532/. Acesso em: 03 mar. 2020.

RIO GRANDE DO SUL. Carazinho. $1^{a}$ Vara Cível. Ação Indenizatória. Processo $\mathrm{n}^{\mathrm{o}}$ 009/1.07.0007296-3. 28 jan. 2009. Diário de Justiça, Porto Alegre, 11 fev. 2009. Disponível em: http://www1.tjrs.jus.br/site_php/consulta/consulta_sentenca.php?id_comarca=carazin ho\&num_processo $=10700072963 \&$ code $=9384 \&$ nomecomarca $=$ CARAZINHO\&orgao $=1 \%$ AA\%20Vara\%20C\%EDvel\%20:\%201\%20/\%201. Acesso em: 03 mar. 2020 .

RIO GRANDE DO SUL. Tribunal de Justiça. Apelação Cível. Processo $n^{\circ} 70067503557$. Relator: Miguel Ângelo da Silva. 19 out. 2016. Diário de Justiça, Porto Alegre, 25 out. 2016. Disponível em: https://tj-rs.jusbrasil.com.br/jurisprudencia/398598550/apelacao-civelac70067503557-rs. Acesso em: 03 mar. 2020.

SUPERIOR TRIBUNAL DE JUSTIÇA. REsp 1.026.981/RJ 2008/0025171-7. $3^{\text {a }}$ Turma, Rel. Min. Nancy Andrighi, J. J.04.2010. Disponível em: https://stj.jusbrasil.com.br/jurisprudencia/19165773/recurso-especial-resp-1026981-rj-2008-00251717/inteiro-teor-19165774. Acesso em: 03 mar. 2020. 
SUPERIOR TRIBUNAL DE JUSTIÇA. REsp 1.159.242/SP 2009/0193701-9. Rel. Min. Nancy Andrighi. J. 10.05.2012. Disponível em: https://www.migalhas.com.br/arquivo_artigo/art20120510-02.pdf. Acesso em: 03 mar. 2020.

TARTUCE, Flávio . Manual de Direito Civil. 9. ed. rev. e ampl. Rio de Janeiro: Forense, 2019.

VATANABE, Juliane Hellmann. O abandono digital infantil como hipótese de negligência prevista no artigo 98, inciso II, do Estatuto da Criança e do Adolescente. $58 \mathrm{f}$. Monografia (Bacharelado em Direito) - Universidade Federal de Rondônia, Cacoal, 2017.

Disponível em: http://www.ri.unir.br/jspui/bitstream/123456789/2242/1/JULIANE\%20HELLMANN\%20VA TANABE.pdf. Acesso em: 04 abr. 2020.

VENOSA, Sílvio de Salvo. Direito Civil: direito de família. 7. ed. São Paulo: Atlas, 2007. v. 6. (Coleção Direito Civil). 